\begin{tabular}{cc|c}
\hline Tar. Bil. Der. & Journal of Agricultural Sciences \\
& $\begin{array}{c}\text { Dergi web sayfası: } \\
\text { www.agri.ankara.edu.tr/dergi }\end{array}$ & Journal homepage: \\
& www.agri.ankara.edu.tr/journal
\end{tabular}

\title{
Bazı Organik Besin Kaynaklarının Cin Mısırın (Zea mays L. everta) Tane Verimine Etkisi
}

\author{
Haktan CIHANGIR ${ }^{\mathrm{a}}$, Abdullah ÖKTEM ${ }^{\mathrm{b}}$ \\ ${ }^{a}$ Tarım ve Kirsal Kalkınmayı Destekleme Kurumu Mardin Il Koordinatörlüğ̈̈, Yenişehir, Mardin, TÜRKIYE \\ ${ }^{\boldsymbol{b}}$ Harran Üniversitesi, Ziraat Fakültesi, Tarla Bitkileri Bölümü, Osmanbey Kampüsü, Şanlıurfa, TÜRKiYE
}

\section{ESER BILLİSI}

Araştırma Makalesi $\quad$ DOI: 10.15832/ankutbd.446383

Sorumlu Yazar: Haktan CiHANGIR, E-posta: haktancihangir@gmail.com, Tel: +90 (532) 3501592

Geliş Tarihi: 06 Şubat 2015, Düzeltmelerin Gelişi: 13 Haziran 2016, Kabul: 14 Temmuz 2016

\section{ÖZET}

$\mathrm{Bu}$ çalışma 16 farklı organik besin kaynağının cin mısırının (Zea mays L. everta) tane verimine etkisini belirlemek amacıyla Diyarbakır'ın Çermik ilçesinde 2010 ve 2011 yıllarında yürütülmüştür. Araştırma tesadüf blokları deneme desenine göre 3 tekerrürlü olarak kurulmuş ve bitkisel materyal olarak Ant-Cin 98 cin mısırı çeşidi kullanılmıştır. Araştırmada geleneksel yöntem dışında organik besin maddeleri olarak torf, kompost, sığır gübresi, tavuk gübresi, at gübresi, koyun gübresi, güvercin gübresi, solucan gübresi, deniz yosunu gübresi + sığır gübresi, kompost + humik asit, sığır gübresi + humik asit, tavuk gübresi + humik asit, at gübresi + humik asit, koyun gübresi + humik asit, torf + humik asit kullanılmıştır. Her iki yılda da uygulamaların cin mısır verimini istatistiksel olarak önemli ölçüde etkilediği belirlenmiştir $(\mathrm{P} \leq 0.01)$. İki yılın ortalamasında en yüksek cin mısır tane verimi sırasıyla; deniz yosunu + sığır gübresi, at gübresi + humik asit, koyun gübresi + humik asit uygulamalarından elde edilmiştir. Bu uygulamaların tane verimleri sırasıyla; $526.54 \mathrm{~kg} \mathrm{da}^{-1}, 516.85 \mathrm{~kg} \mathrm{da}^{-1}$ ve $497.07 \mathrm{~kg} \mathrm{da}^{-1}$ olmuştur. Deniz yosunu + sığır gübresi, at gübresi + humik asit, koyun gübresi + humik asit ve güvercin gübresi uygulamalarına ait tane veriminde, geleneksele göre sırasıyla $\% 9.47$, \% 7.45, \% 3.34 ile \% 0.52'e varan verim artış1 oluşmuştur. Çalışmada ayrıca ekonomik kârlılık durumu da belirlenmiştir. Dekardan en fazla net kâr sağlayan uygulama 2010 y1lında at gübresi + humik asit (2280.64 TL da-1), 2011 y1lında ise at gübresi (2545.82 $\left.\mathrm{TL} \mathrm{da}^{-1}\right)$ uygulamaları olmuştur. Verim, kalite ve net ekonomik kârlılık göz önüne alındığında; at gübresi, tavuk gübresi, kompost, sığır gübresi, koyun gübresi ile humik asit uygulamaları organik cin mısır tarımında kullanılabilir.

Anahtar Kelimeler: Cin mısır; Organik gübre; Humik asit; Tane verimi

\section{Effects of Some Organic Nutrient Sources on Grain Yield of Popcorn (Zea mays L. everta)}

\section{ARTICLE INFO}

Research Article

Corresponding Author: Haktan CIHANGİR, E-mail: haktancihangir@gmail.com, Tel: +90 (532) 3501592

Received: 06 February 2015, Received in Revised Form: 13 June 2016, Accepted: 14 July 2016 


\begin{abstract}
This study was carried out to determine effect of sixteen different organic nutrition sources to grain yield of popcorn (Zea mays L. everta) in Çermik district of Diyarbakır province of Turkey between 2010 and 2011 years. The research was established according to Randomized Complete Block Designs (RCBD) with 3 replicates and Ant-Cin 98 popcorn variety was used as crop material in the study. Organic nutrition sources were torf, compost, cattle manure, chicken manure, horse manure, sheep manure, pigeon manure, vermicompost, seaweed + cattle manure, compost + humic acid, cattle manure + humic acid, chicken manure + humic acid, horse manure + humic acid, sheep manure + humic acid and torf + humic acid except conventional. In both years, applications affected significantly popcorn yield $(\mathrm{P} \leq 0.01)$. According to average of two years, the highest popcorn grain yields were found at seaweed + cattle manure, horse manure + humic acid and sheep manure + humic acid applications. Grain yields of these applications were $526.54 \mathrm{~kg} \mathrm{da}^{-1}, 516.85 \mathrm{~kg}^{-}$ $\mathrm{da}^{-1}$ and $497.07 \mathrm{~kg} \mathrm{da}^{-1}$, respectively. Seaweed + cattle manure, horse manure + humic acid, sheep manure + humic acid and pigeon manure of applications were caused a $9.47 \%, 7.45 \%, 3.34 \%, 0.52 \%$ increase in yield compared with the conventional application, respectively. Also economic analysis was performed in this study. The greatest net profits were obtained from horse manure + humic acid application (2280.64 TL da $\left.{ }^{-1}\right)$ in 2010 while horse manure $\left(2545.82 \mathrm{TL} \mathrm{da}^{-1}\right)$ application in 2011. According to yield, quality and economic net profit; horse manure, chicken manure, compost, cattle manure, sheep manure and humic acid applications can be used in organic popcorn farming.
\end{abstract}

Keywords: Popcorn; Organic manure; Humic acid; Grain yield

(C) Ankara Üniversitesi Ziraat Fakültesi

\section{Giriş}

Cin mısırı patlatılarak doğrudan insan beslenmesinde kullanılmaktadır. Ülkemizde cin mısırın ekiliş alanı, üretim ve tüketim miktarı ile ilgili herhangi bir istatistiğe rastlanmamıştır. Adana, Çanakkale, Adapazarı, Antalya, Isparta ve Burdur illeri çevresinde, Ege ve Akdeniz Bölgelerinde ekiminin yapıldığ bildirilmektedir (Kün 1997). Mısır tarımının yapıldığı bölgelerde cin mısırının yetiştirilebileceği belirtilmektedir (Öktem 1997; Ülger 1998). Cin mısırının tüketimi son yıllarda artış göstermiş olup üretime olan talepte her geçen gün artmaktadır. Tüketicilerin organik olarak yetiştirilmiş ürünlere rağbet etme eğilimleri sürekli artı̧̧ göstermektedir. Cin misırının doğrudan insanlar tarafindan tüketilmesi nedeniyle organik cin mısırı ürününe olan talebin daha fazla olduğu görülmektedir. Önümüzdeki yıllarda organik yetiştirilmiş cin mısırına olan talebin artarak devam edeceği tahmin edilmektedir. GAP bölgesinde sentetik kimyasalların az kullanılması, doğal şartlarda çeşitli ürünlerin yetiştiriliyor olması, tarım alanlarının kirlenmemiş olması nedeniyle büyük bir organik tarım potansiyeli bulunmaktadır.
Organik tarımda kullanılabilecek en önemli bitki besin maddesi kaynakları büyükbaş, küçükbaş ve kanatlı hayvan gübreleri ile bitkisel atıkların olduğu bilinmektedir. Son yıllarda organik tarımda kullanılan gübrelerin yelpazesi genişlemiş ve kompost, humik ve fulvik asit, leonardit gibi organik materyallere ilave olarak içerisinde çeşitli mikroorganizma türleri, enzimleri ve yosun ekstraktları içeren gübreler ticari boyutta üretilmeye başlanmıştır.

Çalışma konusu ile ilgili olarak dünyanın farklı bölgelerinde yapılan araştırmalarda farklı sonuçlar elde edilmiştir. Anaç \& Okur (1996), organik gübre olarak Biofarm (sertifikalı organik gübre) ve çiftlik (sertifikasız) gübresinin deneme topraklarına uygulanması ile mısır bitkisinin kuru ağırlık, mineral içeriği ve veriminin kontrole göre belirgin artış gösterdiğini ve istatistiksel anlamda önemli olduğunu $(\mathrm{P}<0.001)$ bildirmişlerdir. Delate \& Combardella (2000), geleneksel ve organik gübrenin mısır bitkisinin verimi üzerine etkisini belirlemek amacıyla bir çalışma yapmışlardır. Araştırmacılar yürüttükleri çalışma sonucunda, organik olarak yetiştirilen misır bitkisinden elde ettikleri verimin $\left(903.1 \mathrm{~kg} \mathrm{da}^{-1}\right)$, geleneksel olarak 
yetiştirilen misır bitkisine nazaran $\left(884.3 \mathrm{~kg} \mathrm{da}^{-1}\right)$ daha fazla olduğunu bildirmişlerdir.

Neill \& Robinson (2001), geleneksel, sığır gübresi, tavuk gübresi ve herhangi bir gübrenin uygulanmadığı bir çalışma sonucunda, sığır gübresinin uygulandiğı parsellerden elde edilen tane veriminin diğer uygulamalara göre daha iyi sonuç verdiğini ifade etmişlerdir. Wang et al (2003), organik gübrenin $\% 26$, sentetik gübrenin de misır verimine \% 74 katkı sağladığını bildirmişlerdir. Sharif et al (2004), en yüksek tane verimini organik gübre ve inorganik gübreye humik asit ilave edilmesi sonucunda elde etmişlerdir. Prasanna et al (2007), en yüksek tane verimini solucan gübre uygulamasindan; Shafiq-ur-Rehman et al (2008) ise kimyasal gübrenin uygulandığ yüksek tane verimini elde ettiklerini bildirmişlerdir.
$\mathrm{Bu}$ çalışmada, organik tarıma yönelik kullanılan bazı organik besin kaynaklarının cin misırın tane verimi üzerine etkisini ve ekonomik anlamda en uygun organik besin kaynağını belirlemek amaçlanmıştır.

\section{Materyal ve Yöntem}

Araştırma Diyarbakır ili Çermik İlçesi Aşağışeyhler köyünde 2010 ve 2011 yıllarında II. ürün koşullarında yürütülmüştür. Araştırmanın yürütüldüğü 2010 ve 2011 yılları ile uzun yıllara ait iklim değerleri Çizelge 1 'de verilmiştir. Ekimden önce deneme alanından 0-30 cm derinlikten toprak örneği alınarak toprağın fiziksel ve kimyasal özellikleri belirlenmiştir. Deneme alanının bazı fiziksel ve kimyasal özellikleri Çizelge 2'de verilmiştir. Çizelge 2'de görüleceği üzere deneme alanının toprağı kırmızı-kahverengi

Çizelge 1- Diyarbakır ilinde 2010, 2011 ve uzun yıllar ortalamasına ait yağış sıcaklık ve nispi nem değerleri

\begin{tabular}{|c|c|c|c|c|c|c|}
\hline Aylar & Yillar & $\begin{array}{l}\text { Minimum } \\
\text { sicaklık } \\
\left({ }^{\circ} \mathrm{C}\right)\end{array}$ & $\begin{array}{l}\text { Maksimum } \\
\text { slcaklık } \\
\left({ }^{\circ} \mathrm{C}\right)\end{array}$ & $\begin{array}{c}\text { Ortalama } \\
\text { sicaklık } \\
\left({ }^{\circ} \mathrm{C}\right)\end{array}$ & $\begin{array}{l}Y a \breve{g} l s \\
(\mathrm{~mm})\end{array}$ & $\begin{array}{l}\text { Nispi nem } \\
\text { (\%) }\end{array}$ \\
\hline Haziran & $\begin{array}{c}2010 \\
2011 \\
\text { Uzun y1llar }\end{array}$ & $\begin{array}{l}14.9 \\
13.2 \\
16.9\end{array}$ & $\begin{array}{l}40.8 \\
37.9 \\
33.7\end{array}$ & $\begin{array}{l}27.2 \\
26.3 \\
26.3\end{array}$ & $\begin{array}{c}8.0 \\
14.6 \\
7.2\end{array}$ & $\begin{array}{l}47.6 \\
33.9 \\
36.0\end{array}$ \\
\hline Temmuz & $\begin{array}{c}2010 \\
2011 \\
\text { Uzun y1llar }\end{array}$ & $\begin{array}{l}18.0 \\
18.4 \\
21.7\end{array}$ & $\begin{array}{l}44.0 \\
45.0 \\
38.5\end{array}$ & $\begin{array}{l}32.7 \\
31.5 \\
31.2\end{array}$ & $\begin{array}{l}0.0 \\
0.2 \\
0.7\end{array}$ & $\begin{array}{l}34.3 \\
22.6 \\
27.0\end{array}$ \\
\hline Ağustos & $\begin{array}{c}2010 \\
2011 \\
\text { Uzun yıllar }\end{array}$ & $\begin{array}{l}18.0 \\
16.0 \\
21.0\end{array}$ & $\begin{array}{l}43.6 \\
43.5 \\
38.1\end{array}$ & $\begin{array}{l}32.4 \\
31.2 \\
30.3\end{array}$ & $\begin{array}{l}0.0 \\
0.0 \\
0.3\end{array}$ & $\begin{array}{l}32.2 \\
22.3 \\
27.0\end{array}$ \\
\hline Eylül & $\begin{array}{c}2010 \\
2011 \\
\text { Uzun y1llar }\end{array}$ & $\begin{array}{l}13.6 \\
12.8 \\
16.0\end{array}$ & $\begin{array}{l}41.2 \\
38.1 \\
33.1\end{array}$ & $\begin{array}{l}26.8 \\
25.6 \\
24.8\end{array}$ & $\begin{array}{l}3.0 \\
1.9 \\
2.6\end{array}$ & $\begin{array}{l}44.7 \\
28.5 \\
31.0\end{array}$ \\
\hline Ekim & $\begin{array}{c}2010 \\
2011 \\
\text { Uzun y1llar }\end{array}$ & $\begin{array}{c}7.3 \\
3.0 \\
10.1\end{array}$ & $\begin{array}{l}30.0 \\
32.8 \\
25.3\end{array}$ & $\begin{array}{l}17.6 \\
17.4 \\
17.2\end{array}$ & $\begin{array}{l}49.2 \\
57.4 \\
30.8\end{array}$ & $\begin{array}{l}61.8 \\
52.5 \\
48.0\end{array}$ \\
\hline Kasım & $\begin{array}{c}2010 \\
2011 \\
\text { Uzun y1llar }\end{array}$ & $\begin{array}{r}1.0 \\
-4.7 \\
3.6\end{array}$ & $\begin{array}{l}26.1 \\
19.9 \\
15.9\end{array}$ & $\begin{array}{c}12.0 \\
6.6 \\
9.3\end{array}$ & $\begin{array}{c}0.0 \\
104.0 \\
54.6\end{array}$ & $\begin{array}{l}57.4 \\
61.1 \\
68.0\end{array}$ \\
\hline
\end{tabular}

Kaynak: Diyarbakır Meteoroloji Bölge Müdürlüğü (Anonim 2011).

Çizelge 2- Denemenin yapıldığı alanın 0-30 cm'deki toprak özellikleri

\begin{tabular}{|c|c|c|c|c|c|c|c|c|c|}
\hline $\begin{array}{l}\text { Derinlik } \\
(\mathrm{cm})\end{array}$ & Bünye & Toprak rengi & $p H$ & $\begin{array}{c}\text { Su ile } \\
\text { doygunluk } \\
\text { (\%) }\end{array}$ & $\begin{array}{c}\text { Toplam } \\
\text { tuz } \\
(\%)\end{array}$ & $\begin{array}{l}\text { Organik } \\
\text { madde } \\
(\%)\end{array}$ & $\begin{array}{c}\mathrm{CaCO}_{3} \\
(\%)\end{array}$ & $\begin{array}{c}\text { Yaraylısll } \\
\mathrm{P}_{2} \mathrm{O}_{5} \\
\left(\mathrm{~kg} d a^{-1}\right)\end{array}$ & 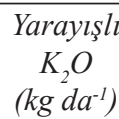 \\
\hline 30 & Killi-tınl & Kırmızı-kahve & 7.4 & 64.9 & 0.03 & 1.19 & 9.08 & 2.75 & 82.05 \\
\hline
\end{tabular}


olup, toprak tekstürü ise killi-tınlıdır. Deneme alanı toprağının tuz oranı düşük, organik madde ve fosfor miktarı yetersiz, potasyum ve kireç oranı fazla ve hafif alkali karakterde olduğu belirlenmiştir.

Çalışmada bitkisel materyal olarak AntCin-98 cin mısır çeşidi kullanılmıştır. Denemede organik yöntemlerle üretilmiş ve organik tarımda kullanılabilirlik sertifikası olan organik materyallerden yararlanılmıştır. Denemede kullanılan organik gübre materyalleri organik tarımın esasları ve uygulanmasına ilişkin yönetmeliğinin 20 . maddesi gereğince arazi üzerine verilecek azami saf azot miktarına göre $\left(17 \mathrm{~kg} \mathrm{da}^{-1}\right)$ hesaplanarak uygulanmıştır (Resmi gazete 2010). Geleneksel gübre uygulamasında dekara saf olarak $17 \mathrm{~kg} \mathrm{da}^{-1}$ azot, $8 \mathrm{~kg} \mathrm{da}^{-1}$ fosfor ve potasyum verilmiştir. Organik besin maddeleri olarak torf, kompost, sığır gübresi, tavuk gübresi, at gübresi, koyun gübresi, güvercin gübresi, solucan gübresi, deniz yosunu gübresi + sığır gübresi, kompost + humik asit, sığır gübresi + humik asit, tavuk gübresi + humik asit, at gübresi + humik asit, koyun gübresi + humik asit, torf + humik asit kullanılmıştır. Araştırmada kullanılan besin kaynakları azot içeriği ile dekara atılan gübre miktarları Çizelge 3 'te verilmiştir.

Deneme kurulan alanın organik tarıma uygun hale getirilmesi için, deneme alanına 2008 ve 2009 yıllarında buğday ekilmiş, hiçbir kimyasal gübre ve ilaç uygulanmadan buğday yetiştirilerek hasat edilmiştir. Ekimden önce toprak goble disk ve ardından diskaro ile işlenerek ekime hazır hale getirilmiştir. Deneme Yurtsever (1984)'e göre tesadüf blokları deneme desenine göre üç tekrarlamalı olarak kurulmuştur. Her parsel $(5 \mathrm{~m}$ x $2.80 \mathrm{~m}) 4$ sıradan meydana gelmiştir. Ekimde sıra arası mesafeler $70 \mathrm{~cm}$ ve sıra üzeri mesafeler $20 \mathrm{~cm}$ olmuştur. Besin kaynaklarının çoğu ekim öncesi ve ekimle birlikte, deniz yosunu gübresi ise bir kısmı ekim öncesi toprağa, geri kalanı ise bitkiler $20 \mathrm{~cm}$ boya ulaştıktan sonra birer hafta ara ile üç kez olmak üzere yapraktan uygulanmıştır. 1530 Haziran tarihleri arasında cin misır tohumları 5-6 cm derinliğe elle ekilmiştir. Çıkış için yeterli düzeyde nem bulunmadığı için ekimden sonra yağmurlama sulama, yetişme süresi boyunca da karık usulü sulama ile parsellere eşit miktarda su verilmiştir. Parseller arası su geçişini engellemek

Çizelge 3- Organik besin kaynaklarının azot içeriği ile dekara uygulanan miktarları

\begin{tabular}{llcl}
\hline & Besin kaynakları & $\begin{array}{c}\text { Niçeriği } \\
(\%)\end{array}$ & Uygulanan miktar \\
\hline 1 & Geleneksel gübre (üre) & 46 & $36.96 \mathrm{~kg} \mathrm{da}^{-1}$ \\
2 & Torf & 1.2 & $1416 \mathrm{~kg} \mathrm{da}^{-1}$ \\
3 & Kompost & 2.5 & $680 \mathrm{~kg} \mathrm{da}^{-1}$ \\
4 & Siğır gübresi & 3.5 & $486 \mathrm{~kg} \mathrm{da}^{-1}$ \\
5 & Tavuk gübresi & 3.0 & $567 \mathrm{~kg} \mathrm{da}^{-1}$ \\
6 & At gübresi & 2.0 & $850 \mathrm{~kg} \mathrm{da}^{-1}$ \\
7 & Koyun gübresi & 2.0 & $850 \mathrm{~kg} \mathrm{da}^{-1}$ \\
8 & Güvercin gübresi & 6.0 & $283 \mathrm{~kg} \mathrm{da}^{-1}$ \\
9 & Deniz yosunu + sığır gübresi & $2.0+3.5$ & $51.5 \mathrm{~kg} \mathrm{da}^{-1}+457 \mathrm{~kg} \mathrm{da}^{-1}$ \\
10 & Solucan gübresi & 1.5 & $1133 \mathrm{~kg} \mathrm{da}^{-1}$ \\
11 & Kompost + humik asit & 2.5 & $680 \mathrm{~kg} \mathrm{da}^{-1}+140 \mathrm{~g} \mathrm{da}^{-1}$ \\
12 & Siğır gübresi + humik asit & 3.5 & $486 \mathrm{~kg} \mathrm{da}^{-1}+140 \mathrm{~g} \mathrm{da}^{-1}$ \\
13 & Tavuk gübresi + humik asit & 3.0 & $567 \mathrm{~kg} \mathrm{da}^{-1}+140 \mathrm{~g} \mathrm{da}^{-1}$ \\
14 & Koyun gübresi + humik asit & 2.0 & $850 \mathrm{~kg} \mathrm{da}^{-1}+140 \mathrm{~g} \mathrm{da}^{-1}$ \\
15 & Torf + humik asit & 1.2 & $1416 \mathrm{~kg} \mathrm{da}^{-1}+140 \mathrm{~g} \mathrm{da}^{-1}$ \\
16 & At gübresi + humik asit & 2.0 & $850 \mathrm{~kg} \mathrm{da}^{-1}+140 \mathrm{~g} \mathrm{da}^{-1}$ \\
\hline
\end{tabular}

Tarım Bilimleri Dergisi - Journal of Agricultural Sciences $\quad \mathbf{2 4}$ (2018)60-71 
için parseller arasında 2 metre boşluk bırakılmış ve parsellerin etrafi sedde ile çevrilmiştir. Bitki koruma ve bakım yöntemi olarak doğal kültürel önlemler (çimlenmeden sonra tekleme ardından traktör ve el çapası) yapılmıştır. Ayrıca mısır koçan kurdu zararlısına karşı Trichogramma sp. faydalı böceği kullanılmıştır. Hasat sırasında parselin her iki başından $0.5 \mathrm{~m}$ ve her iki kenarında bulunan birer sıra kenar tesiri olarak atılarak hasat edilmiş ve ortadaki iki sıradan değerler alınmıştır. Elde edilen değerler Totemstat-C paket programı kullanılarak varyans analizine ve Duncan çoklu karşılaştırmasına tabii tutulmuştur (Açıkgöz et al 2004). Ayrıca kullanılan besin maddelerinin hangisinin daha ekonomik olduğunu belirlemek için Vuruş et al (2000)'ın belirttiği şekilde ekonomik analiz de yapılmıştır.

\section{Bulgular ve Tartışma}

\subsection{Tane verimi}

Organik olarak yetiştirilen cin mısırda tane verimi ile ilgili varyans analiz değerleri Çizelge 4'de görülmektedir. Araştırmada yıllar ayrı ayrı ve birleştirilerek varyans analizine tabi tutulmuştur. Tane verimi bakımından besin kaynakları arasındaki farklılık 2010 y1lı ve 2011 yılında \% 1 düzeyinde önemli bulunmuştur. İki yılın birleştirilmiş varyans analizinde ise tane verimi bakımından, yıllar, besin kaynakları ve yıl x besin kaynakları interaksiyonu $\% 1$ düzeyinde istatistiki olarak önemli bulunmuştur (Çizelge 4). Tane verimine ait ortalama değerler ve Duncan çoklu karşılaştırma testine göre oluşan gruplar Çizelge 5'te verilmiştir. 2010-2011 y1lı

Çizelge 4- Tane verimine ait 2010, 2011 ve 2010-2011 birleştirilmiş varyans analizi tablosu

\begin{tabular}{|c|c|c|c|c|c|c|}
\hline \multicolumn{7}{|c|}{2010} \\
\hline $\begin{array}{l}\text { Varyasyon } \\
\text { kaynakları }\end{array}$ & $\begin{array}{l}\text { Serbestlik } \\
\text { derecesi }\end{array}$ & $\begin{array}{l}\text { Kareler } \\
\text { toplamı }\end{array}$ & $\begin{array}{c}\text { Kareler } \\
\text { ortalaması }\end{array}$ & $\begin{array}{l}\text { Hesaplanan } \\
\qquad F \text { değeri }\end{array}$ & $\begin{array}{c}\text { Tablo } \\
\text { değeri } \\
\% 5\end{array}$ & $\begin{array}{c}\text { Tablo } \\
\text { değeri } \\
\% 1\end{array}$ \\
\hline Tekerrür & 2 & 586.351 & 293.176 & 0.604 öd & 3.320 & 5.390 \\
\hline Besin kaynakları & 15 & 76752.585 & 5116.839 & $10.548 * *$ & 2.010 & 2.700 \\
\hline Hatal & 30 & 14552.362 & 485.079 & & & \\
\hline Genel & 47 & 91891.298 & & & & \\
\hline Değişsim katsayısı & $\mathrm{CV}=\% 5.33$ & & & & & \\
\hline \multicolumn{7}{|c|}{2011} \\
\hline $\begin{array}{l}\text { Varyasyon } \\
\text { kaynaklart }\end{array}$ & $\begin{array}{c}\text { Serbestlik } \\
\text { derecesi }\end{array}$ & $\begin{array}{l}\text { Kareler } \\
\text { Toplamı }\end{array}$ & $\begin{array}{c}\text { Kareler } \\
\text { ortalaması }\end{array}$ & $\begin{array}{c}\text { Hesaplanan } \\
F \text { değeri }\end{array}$ & $\begin{array}{c}\text { Tablo } \\
\text { değeri } \\
\% 5\end{array}$ & $\begin{array}{c}\text { Tablo } \\
\text { değeri } \\
\% 1\end{array}$ \\
\hline Tekerrür & 2 & 1544.856 & 772.428 & 1.602 öd & 3.320 & 5.390 \\
\hline Besin kaynakları & 15 & 70876.194 & 4725.080 & $9.801 * *$ & 2.010 & 2.700 \\
\hline Hata1 & 30 & 14463.127 & 482.104 & & & \\
\hline Genel & 47 & 86884.177 & & & & \\
\hline Değişisim katsayısı & $\mathrm{CV}=\% 4.26$ & & & & & \\
\hline \multicolumn{7}{|c|}{$2010-2011$} \\
\hline $\begin{array}{l}\text { Varyasyon } \\
\text { kaynaklart }\end{array}$ & $\begin{array}{c}\text { Serbestlik } \\
\text { derecesi }\end{array}$ & $\begin{array}{l}\text { Kareler } \\
\text { toplamı }\end{array}$ & $\begin{array}{c}\text { Kareler } \\
\text { ortalamast }\end{array}$ & $\begin{array}{c}\text { Hesaplanan } \\
\text { F değeri }\end{array}$ & $\begin{array}{c}\text { Tablo } \\
\text { değeri } \\
\% 5\end{array}$ & $\begin{array}{c}\text { Tablo } \\
\text { değeri } \\
\% 1\end{array}$ \\
\hline Tekerrür & 2 & 266.948 & 133.474 & 0.143 öd & 19.000 & 99.000 \\
\hline Y1l & 1 & 251745.288 & 251745.288 & $270.076^{* *}$ & 18.510 & 98.500 \\
\hline Hatal & 15 & 1864.258 & 932.129 & & & \\
\hline Besin kaynakları & 15 & 88247.618 & 5883.175 & $12.166 * *$ & 1.840 & 2.350 \\
\hline Y11* besin kaynakları & 62 & 59381.162 & 3958.744 & $8.186 * *$ & 1.840 & 2.350 \\
\hline Hata2 & 95 & 29015.488 & 483.591 & & & \\
\hline Genel & & 430520.762 & & & & \\
\hline Değișim katsayısı & $C V(a)=\% 6.5$ & $\mathrm{CV}(\mathrm{b})=\% 4$ & & & & \\
\hline
\end{tabular}

*, 0.05 'e göre önemli; **, 0.01 'e göre önemli; öd, önemli değil 
Çizelge 5- Farklı organik besin maddesi kaynaklarının cin mısırın tane verimine etkisi

\begin{tabular}{llll}
\hline Besin kaynaklarl & 2010 & 2011 & Ortalama \\
\hline Geleneksel gübre & $390.26 \mathrm{c}-\mathrm{f}^{*}$ & $571.76 \mathrm{a}$ & $481.01 \mathrm{~B}-\mathrm{E}$ \\
Torf & $362.09 \mathrm{f}$ & $480.45 \mathrm{bcd}$ & $421.27 \mathrm{~F}$ \\
Kompost & $372.85 \mathrm{ef}$ & $488.78 \mathrm{bcd}$ & $430.82 \mathrm{~F}$ \\
Sığır gübresi & $419.39 \mathrm{~cd}$ & $472.57 \mathrm{~cd}$ & $445.98 \mathrm{DEF}$ \\
Tavuk gübresi & $379.93 \mathrm{ef}$ & $466.44 \mathrm{~d}$ & $423.18 \mathrm{~F}$ \\
At gübresi & $462.24 \mathrm{ab}$ & $482.79 \mathrm{bcd}$ & $472.52 \mathrm{CDE}$ \\
Koyun gübresi & $408.65 \mathrm{cde}$ & $511.63 \mathrm{bc}$ & $460.14 \mathrm{C}-\mathrm{F}$ \\
Güvercin gübresi & $475.93 \mathrm{a}$ & $491.04 \mathrm{bcd}$ & $483.49 \mathrm{BCD}$ \\
Deniz yosunu + sığır gübresi & $477.06 \mathrm{a}$ & $576.01 \mathrm{a}$ & $526.54 \mathrm{~A}$ \\
Solucan gübresi & $381.66 \mathrm{def}$ & $500.60 \mathrm{bcd}$ & $441.13 \mathrm{EF}$ \\
Kompost + humik asit & $379.58 \mathrm{def}$ & $508.05 \mathrm{bcd}$ & $443.81 \mathrm{EF}$ \\
Siğır gübresi + humik asit & $433.04 \mathrm{bc}$ & $486.03 \mathrm{bcd}$ & $459.54 \mathrm{CF}$ \\
Tavuk gübresi + humik asit & $386.38 \mathrm{def}$ & $516.17 \mathrm{~b}$ & $451.27 \mathrm{DEF}$ \\
Koyun gübresi + humik asit & $433.70 \mathrm{bc}$ & $560.44 \mathrm{a}$ & $497.07 \mathrm{ABC}$ \\
Torf + humik asit & $372.17 \mathrm{ef}$ & $578.28 \mathrm{a}$ & $475.22 \mathrm{CDE}$ \\
At gübresi + humik asit & $475.58 \mathrm{a}$ & $558.12 \mathrm{a}$ & $516.85 \mathrm{AB}$ \\
Ortalama & $413.16 \mathrm{~B}$ & $515.57 \mathrm{~A}$ & \\
\hline & Y11: 0.467 & \\
LSD & $2010 \mathrm{Besin}$ kaynaklar1: 36.721 & \\
& $2011 \mathrm{Besin}$ kaynaklar1: 36.608 & \\
\hline
\end{tabular}

*, aynı harf grubuna giren ortalamalar arasında Duncan Testine göre 0.05 düzeyinde önemli farklılık yoktur

ortalamaları ele alındığında, farklı besin madde uygulamalarında tane verimi $421.27 \mathrm{~kg} \mathrm{da}^{-1}$ ile $526.54 \mathrm{~kg} \mathrm{da}^{-1}$ arasında değişmiştir. Tane verimi değeri en yüksek $526.54 \mathrm{~kg} \mathrm{da}^{-1}$ ile deniz yosunu + sığır gübresi uygulamasından elde edilmiş ve daha sonra sirasıyla, at gübresi + humik asit $(516.85$ $\left.\mathrm{kg} \mathrm{da}^{-1}\right)$ ile koyun gübresi + humik asit (497.07 $\mathrm{kg} \mathrm{da}^{-1}$ ) parsellerinde belirlenmiştir (Çizelge 5). Birleştirilmiş ortalamalarda en düşük tane verimi ise $421.27 \mathrm{~kg} \mathrm{da}^{-1}$ ile torf uygulamasından elde edilmiştir. Yukarıdaki sonuçlardan besin kaynakları içeriğinin, tane verimini olumlu bir şekilde etkilediği ve uygulamalar arasında fark görülmesine sebep olduğu söylenebilir.

Deniz yosunu + sığır gübresi parselinde gübrelerin bir kısmının ekimde geri kalan kısmının ise özellikle yosun gübresinin yapraktan üç dönemde verilmesi, cin mısır koçan özelliklerini (koçan uzunluğu, koçan çapı, koçanda tane sayısı, koçanda tane ağırlığı) olumlu etkilemiş ve sonuçta geleneksel ve diğer organik üretim sistemlerine göre daha fazla tane verimi alınmıştır. Yazıcı \& Kaynak (2001), deniz yosununun organik tarımda verim ve kaliteyi artırdığını belirterek çalışmamızı desteklemektedir. Warman \& Munro-Warman (1993) ise deniz yosunu uygulamasinın misirda verime etkisinin bulunmadığını bildirmektedir. Beşirli et al (2009) domateste en fazla verimi koyun gübresinden aldığını, deniz yosununun tek başına kullanımının verime etkisinin olmadığını, ancak deniz yosunun sığır gübresi, koyun gübresi ve tavuk gübresi gibi materyallerle birlikte uygulanmasının daha uygun olacağını belirtmişlerdir. Çalışmamızda da deniz yosunu gübresi sığır gübresi ile birlikte uygulanmıştır. 
Organik mısır yetiştiriciliğinde tane verimi ile ilgili farklı literatür sonuçları bildirilmiştir. Morris \& Lathwell (2004), Efthimiadou et al (2010) ile Dordas et al (2008) sığır gübresinden; Khan et al (2008), Bamire \& Amujoyegbe (2004) ile Şeker \& Ersoy (2005) tavuk gübresinden; Amujoyegbe et al (2007) ile Mitchell \& Tu (2005) tavuk gübresi + inorganik gübreden; Prasanna et al (2007) solucan gübresinden; Ashoka et al (2009) solucan gübre + kimyasal gübreden; Gürses (2010) yeşil gübreden; Leaungvutivirong et al (2004) organik gübre + kompost uygulamasindan; Amanullah et al (2006) çiftlik gübresi, kümes gübresi ve bunların kombinasyonundan; Lee \& Bartlett (1976) humik asit uygulamasından; Gerzabek \& Ulah (1988) humik asit + çinko uygulamasından; Sharif et al (2004) organik gübre + inorganik gübre + humik asit uygulamasından; Gao et al (2003), Manju \& Mukerji (1994) ve Kan (2005) çiftlik gübresinden; Thakur et al (2009), Wang et al (2003) ile Shafiq-urRehman et al (2008) geleneksel üretim sisteminden; Liu (2003) ile Mahesh et al (2010) organik gübre + inorganik gübreden en yüksek misır tane verimini aldıklarını bildirmişlerdir.

Organik besin kaynakları ile geleneksel yöntemden elde edilen tane verimi arasında meydana gelen \% olarak artış ve azalış oranları hesaplanarak Şekil 1'de verilmiştir. Şekil 1'de yatay düzlem geleneksel üretim sistemi olarak kabul edilmiştir. Şekil 1'de görüldüğü gibi, torf uygulaması, tavuk gübresi ve kompost uygulamalarından elde edilen oransal tane verimi değerleri, geleneksel üretim sistemine göre sirasiyla, \% 12.42, \% 12.02 ve $\% 10.43$ daha düşük bulunmuştur. Buna karşın deniz yosunu + sığır gübresi, at gübresi + humik asit, koyun gübresi + humik asit ve güvercin gübresi uygulamalarından elde edilen oransal tane verim değerleri ise geleneksel üretim sistemine göre sirasiyla, \% 9.47, \% 7.45, \% 3.34 ve \% 0.52 daha yüksek bulunmuştur. Diğer organik uygulamaların tane verimi değerleri bakımından beklenen etkiyi gösteremediği ve geleneksel üretim sisteminden daha düşük verim verdikleri görülmektedir.

\subsection{Ekonomik analiz}

Denemede 2010 yılında cin misır üretimi için belirlenmiş olan dekara 179.98 TL üretim masrafi değeri, üretimde kullanılan organik besin kaynaklarının masraflarına ilave edilmiş ve böylece her bir organik gübre kaynağının toplam genel masrafi elde edilmiştir. Üretim masrafları yönünden uygulamalar karşılaştırıldığında, ortalama değerlere göre en fazla üretim masrafı torf (16454.98 TL $\left.\mathrm{da}^{-1}\right)$ ve torf + humik asit $\left(16504.98 \mathrm{TL} \mathrm{da}^{-1}\right)$ uygulamalarında yapılmıştır. Anılan bu gübrelerin verim değerlerinin geleneksel gübre sistemine yakın

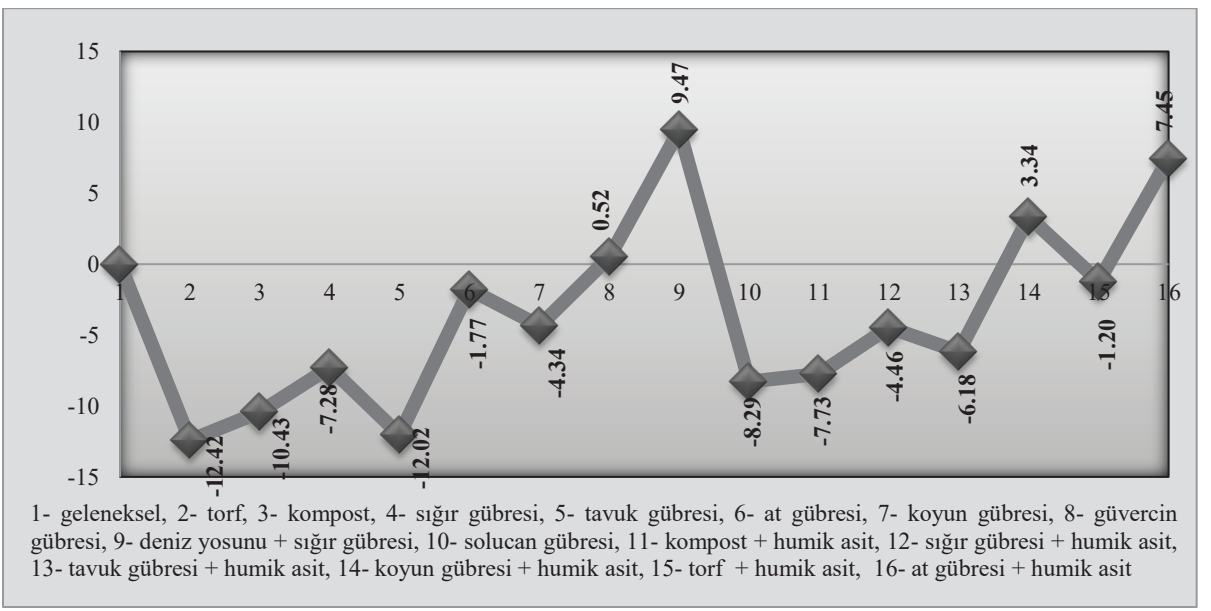

Şekil 1- Farklı organik besin kaynakları ve geleneksel sistemden elde edilen tane veriminin değerlendirilmesi 
olmasına karşılık, üretim masraflarının yüksek olmas1 nedeniyle torf $\left(-14282.44 \mathrm{TL} \mathrm{da}^{-1}\right)$ ve torf + humik asit $\left(-14271.96 \mathrm{TL} \mathrm{da}^{-1}\right)$ uygulamalarında zarar edilmiştir. 2010 yılında üretim masrafı bakımından en ekonomik ve en az masraf olan uygulama $479.98 \mathrm{TL} \mathrm{da}^{-1}$ ile geleneksel gübre uygulamasında saptanmıştır.

Çizelge 6'ya göre cin mısırda 2010 y1lı için bütçe analizi sonucunda ekonomik anlamda en fazla kârlılık 2280.64 TL da ${ }^{-1}$ ile at gübresi + humik asit uygulamasından, en az kârlılık ise $251.13 \mathrm{TL} \mathrm{da}^{-1}$ ile deniz yosunu + sığır gübresi uygulamasından elde edilmiştir. İlk yıl en fazla kârlılık gösteren at gübresi + humik asit (2280.64 TL da $\left.{ }^{-1}\right)$ uygulamasinı daha sonra sirasıyla, at gübresi (2250.60 TL da $\left.{ }^{-1}\right)$, sığır gübresi + humik asit (1868.26 TL da $\left.{ }^{-1}\right)$, sığır gübresi (1836.36 $\left.\mathrm{TL} \mathrm{da}^{-1}\right)$, tavuk gübresi (1528.18 $\left.\mathrm{TL} \mathrm{da}^{-1}\right)$, tavuk gübresi + humik asit $\left(1516.88 \mathrm{TL} \mathrm{da}^{-1}\right)$ ve koyun gübresi + humik asit $\left(1515.08 \mathrm{TL} \mathrm{da}^{-1}\right)$ uygulamaları takip etmiştir.

Çizelge 7'ye göre, 2011 yılı için cin mısır üretimi için belirlenmiş olan dekara 215.16 TL üretim masrafı değeri, üretimde kullanılan organik besin kaynaklarının masraflarına ilave edilmiş ve böylece her bir organik gübre kaynă̆ının toplam genel masrafi elde edilmiştir. Üretim masrafları yönünden uygulamalar karşılaştırıldığında, ortalama değerlere göre en fazla üretim masrafı torf $(17902.50 \mathrm{TL}$ $\left.\mathrm{da}^{-1}\right)$ ve torf + humik asit (17957.50 TL da $\left.\mathrm{da}^{-1}\right)$ uygulamalarında yapılmışıtır. Anılan bu gübrelerin verim değerlerinin geleneksel gübre sistemine yakın olmasına karşılık, üretim masraflarının yüksek olmas1 nedeniyle torf $\left(-14994.74 \mathrm{TL} \mathrm{da}^{-1}\right)$ ve torf + humik asit (-14413.84 $\left.\mathrm{TL} \mathrm{da}^{-1}\right)$ uygulamalarında

\section{Çizelge 6- 2010 Yılı cin mısır ekonomik kârlılık tablosu}

\begin{tabular}{|c|c|c|c|c|c|c|}
\hline \multicolumn{7}{|c|}{2010 Yılı cin misır ekonomik kârlılık tablosu } \\
\hline & Besin kaynaklart & $\begin{array}{c}\text { Genel } \\
\text { masraflar }\end{array}$ & $\begin{array}{c}\text { Besin kaynak- } \\
\text { larının } \\
\text { masrafi }\end{array}$ & $\begin{array}{c}\text { Toplam genel } \\
\text { masraf }\end{array}$ & Gelir* & Kârlılık \\
\hline 1 & Geleneksel gübre & $179.98 \mathrm{TL}$ & $300.00 \mathrm{TL}$ & $479.98 \mathrm{TL}$ & $390.26 \mathrm{~kg} \mathrm{da}^{-1} \times 3.5$ & $885.93 \mathrm{TL}$ \\
\hline 2 & Torf & $179.98 \mathrm{TL}$ & $16275.00 \mathrm{TL}$ & $16454.98 \mathrm{TL}$ & $362.09 \mathrm{~kg} \mathrm{da}^{-1} \times 6.0$ & $-14282.44 \mathrm{TL}$ \\
\hline 3 & Kompost & $179.98 \mathrm{TL}$ & $1357.14 \mathrm{TL}$ & $1537.12 \mathrm{TL}$ & $372.85 \mathrm{~kg} \mathrm{da}^{-1} \times 6.0$ & $699.98 \mathrm{TL}$ \\
\hline 4 & Siğır gübresi & $179.98 \mathrm{TL}$ & $500.00 \mathrm{TL}$ & $679.98 \mathrm{TL}$ & $419.39 \mathrm{~kg} \mathrm{da}^{-1} \times 6.0$ & $1836.36 \mathrm{TL}$ \\
\hline 5 & Tavuk gübresi & $179.98 \mathrm{TL}$ & $571.42 \mathrm{TL}$ & $751.40 \mathrm{TL}$ & $379.93 \mathrm{~kg} \mathrm{da}^{-1} \times 6.0$ & $1528.18 \mathrm{TL}$ \\
\hline 6 & At gübresi & $179.98 \mathrm{TL}$ & $342.86 \mathrm{TL}$ & $522.84 \mathrm{TL}$ & $462.24 \mathrm{~kg} \mathrm{da}^{-1} \times 6.0$ & $2250.60 \mathrm{TL}$ \\
\hline 7 & Koyun gübresi & $179.98 \mathrm{TL}$ & $857.14 \mathrm{TL}$ & $1037.12 \mathrm{TL}$ & $408.65 \mathrm{~kg} \mathrm{da}^{-1} \times 6.0$ & $1414.78 \mathrm{TL}$ \\
\hline 8 & Güvercin gübresi & $179.98 \mathrm{TL}$ & $1928.52 \mathrm{TL}$ & $2108.50 \mathrm{TL}$ & $475.93 \mathrm{~kg} \mathrm{da}^{-1} \times 6.0$ & $747.08 \mathrm{TL}$ \\
\hline 9 & Deniz yosunu + sı̆̆ır gübresi & $179.98 \mathrm{TL}$ & $2431.25 \mathrm{TL}$ & $2611.23 \mathrm{TL}$ & $477.06 \mathrm{~kg} \mathrm{da}^{-1} \times 6.0$ & $251.13 \mathrm{TL}$ \\
\hline 10 & Solucan gübresi & $179.98 \mathrm{TL}$ & $1714.28 \mathrm{TL}$ & $1894.26 \mathrm{TL}$ & $381.66 \mathrm{~kg} \mathrm{da}^{-1} \times 6.0$ & $395.70 \mathrm{TL}$ \\
\hline 11 & Kompost + humik asit & $179.98 \mathrm{TL}$ & $1407.14 \mathrm{TL}$ & $1587.12 \mathrm{TL}$ & $379.58 \mathrm{~kg} \mathrm{da}^{-1} \times 6.0$ & $690.36 \mathrm{TL}$ \\
\hline 12 & Sığır gübresi + humik asit & $179.98 \mathrm{TL}$ & $550.00 \mathrm{TL}$ & $729.98 \mathrm{TL}$ & $433.04 \mathrm{~kg} \mathrm{da}^{-1} \times 6.0$ & $1868.26 \mathrm{TL}$ \\
\hline 13 & Tavuk gübresi + humik asit & $179.98 \mathrm{TL}$ & $621.42 \mathrm{TL}$ & $801.40 \mathrm{TL}$ & $386.38 \mathrm{~kg} \mathrm{da}^{-1} \times 6.0$ & $1516.88 \mathrm{TL}$ \\
\hline 14 & Koyun gübresi + humik asit & $179.98 \mathrm{TL}$ & $907.14 \mathrm{TL}$ & $1087.12 \mathrm{TL}$ & $433.70 \mathrm{~kg} \mathrm{da}^{-1} \times 6.0$ & $1515.08 \mathrm{TL}$ \\
\hline 15 & Torf + humik asit & $179.98 \mathrm{TL}$ & $16325.00 \mathrm{TL}$ & $16504.98 \mathrm{TL}$ & $372.17 \mathrm{~kg} \mathrm{da}^{-1} \times 6.0$ & $-14271.96 \mathrm{TL}$ \\
\hline 16 & At gübresi + humik asit & $179.98 \mathrm{TL}$ & $392.86 \mathrm{TL}$ & $572.84 \mathrm{TL}$ & $475.58 \mathrm{~kg} \mathrm{da}^{-1} \times 6.0$ & $2280.64 \mathrm{TL}$ \\
\hline
\end{tabular}

*, gelir dekardan alınan verim ile ürün bedelinin çarpılması sonucu elde edilmiştir 


\section{Çizelge 7- 2011 Yılı cin mısır ekonomik kârılılık tablosu}

\begin{tabular}{|c|c|c|c|c|c|c|}
\hline \multicolumn{7}{|c|}{2011 Yllı cin misır ekonomik kârlılık tablosu } \\
\hline & Besin kaynakları & $\begin{array}{c}\text { Genel } \\
\text { masraflar }\end{array}$ & $\begin{array}{c}\text { Besin } \\
\text { kaynaklarınin } \\
\text { masrafi }\end{array}$ & $\begin{array}{l}\text { Toplam genel } \\
\text { masraf }\end{array}$ & Gelir* & Kârlılık \\
\hline 1 & Geleneksel gübre & $215.16 \mathrm{TL}$ & $330.00 \mathrm{TL}$ & $545.16 \mathrm{TL}$ & $571.76 \mathrm{~kg} \mathrm{da}^{-1} \times 4.00$ & $1741.88 \mathrm{TL}$ \\
\hline 2 & Torf & $215.16 \mathrm{TL}$ & $17902.50 \mathrm{TL}$ & $18117.66 \mathrm{TL}$ & $480.45 \mathrm{~kg} \mathrm{da}^{-1} \times 6.05$ & $-14994.74 \mathrm{TL}$ \\
\hline 3 & Kompost & $215.16 \mathrm{TL}$ & $1492.85 \mathrm{TL}$ & $1708.01 \mathrm{TL}$ & $488.78 \mathrm{~kg} \mathrm{da}^{-1} \times 6.05$ & $1469.06 \mathrm{TL}$ \\
\hline 4 & Sığır gübresi & $215.16 \mathrm{TL}$ & $550.00 \mathrm{TL}$ & $765.16 \mathrm{TL}$ & $472.57 \mathrm{~kg} \mathrm{da}^{-1} \times 6.05$ & $2306.54 \mathrm{TL}$ \\
\hline 5 & Tavuk gübresi & $215.16 \mathrm{TL}$ & $628.56 \mathrm{TL}$ & $843.72 \mathrm{TL}$ & $466.44 \mathrm{~kg} \mathrm{da}^{-1} \times 6.05$ & $2188.14 \mathrm{TL}$ \\
\hline 6 & At gübresi & $215.16 \mathrm{TL}$ & $377.15 \mathrm{TL}$ & $592.31 \mathrm{TL}$ & $482.79 \mathrm{~kg} \mathrm{da}^{-1} \times 6.05$ & $2545.82 \mathrm{TL}$ \\
\hline 7 & Koyun gübresi & $215.16 \mathrm{TL}$ & $942.85 \mathrm{TL}$ & $1158.01 \mathrm{TL}$ & $511.63 \mathrm{~kg} \mathrm{da}^{-1} \times 6.05$ & $2167.58 \mathrm{TL}$ \\
\hline 8 & Güvercin gübresi & $215.16 \mathrm{TL}$ & $2121.37 \mathrm{TL}$ & $2336.53 \mathrm{TL}$ & $491.04 \mathrm{~kg} \mathrm{da}^{-1} \times 6.05$ & $855.23 \mathrm{TL}$ \\
\hline 9 & Deniz yosunu + sığır gübresi & $215.16 \mathrm{TL}$ & $2674.38 \mathrm{TL}$ & $2889.54 \mathrm{TL}$ & $576.01 \mathrm{~kg} \mathrm{da}^{-1} \times 6.05$ & $854.52 \mathrm{TL}$ \\
\hline 10 & Solucan gübresi & $215.16 \mathrm{TL}$ & $1885.71 \mathrm{TL}$ & $2100.87 \mathrm{TL}$ & $500.60 \mathrm{~kg} \mathrm{da}^{-1} \times 6.05$ & $1153.03 \mathrm{TL}$ \\
\hline 11 & Kompost + humik asit & $215.16 \mathrm{TL}$ & $1547.85 \mathrm{TL}$ & $1763.01 \mathrm{TL}$ & $508.05 \mathrm{~kg} \mathrm{da}^{-1}$ x 6.05 & $1539.31 \mathrm{TL}$ \\
\hline 12 & Sığır gübresi + humik asit & $215.16 \mathrm{TL}$ & $605.00 \mathrm{TL}$ & $820.16 \mathrm{TL}$ & $486.03 \mathrm{~kg} \mathrm{da}^{-1}$ x 6.05 & $2339.03 \mathrm{TL}$ \\
\hline 13 & Tavuk gübresi + humik asit & $215.16 \mathrm{TL}$ & $683.56 \mathrm{TL}$ & $898.72 \mathrm{TL}$ & $516.17 \mathrm{~kg} \mathrm{da}^{-1} \times 6.05$ & $2456.38 \mathrm{TL}$ \\
\hline 14 & Koyun gübresi + humik asit & $215.16 \mathrm{TL}$ & $997.85 \mathrm{TL}$ & $1213.01 \mathrm{TL}$ & $560.44 \mathrm{~kg} \mathrm{da}^{-1}$ x 6.05 & $2429.85 \mathrm{TL}$ \\
\hline 15 & Torf + humik asit & $215.16 \mathrm{TL}$ & $17957.50 \mathrm{TL}$ & $18172.66 \mathrm{TL}$ & $578.28 \mathrm{~kg} \mathrm{da}^{-1}$ x 6.05 & $-14413.84 \mathrm{TL}$ \\
\hline 16 & At gübresi + humik asit & $215.16 \mathrm{TL}$ & $432.15 \mathrm{TL}$ & $647.31 \mathrm{TL}$ & $558.12 \mathrm{~kg} \mathrm{da}^{-1} \times 6.05$ & $2280.64 \mathrm{TL}$ \\
\hline
\end{tabular}

*, gelir dekardan alınan verim ile ürün bedelinin çarpılması sonucu elde edilmiştir

zarar edilmiştir. 2011 yılında üretim masrafı bakımından en ekonomik ve en az masraf olan uygulama $545.16 \mathrm{TL} \mathrm{da}^{-1}$ ile geleneksel gübre uygulamasında saptanmıştır.

Yapılan bütçe analizi sonucunda 2011 yılı için ekonomik anlamda en kârlı üretim $2545.82 \mathrm{TL} \mathrm{da}^{-1}$ ile at gübresi uygulamasından elde edilmiş olup bunu sirasıyla; tavuk gübresi + humik asit (2456.38 $\left.\mathrm{TL} \mathrm{da}^{-1}\right)$, koyun gübresi + humik asit (2429.85 TL $\left.\mathrm{da}^{-1}\right)$, sığır gübresi + humik asit (2339.03 $\left.\mathrm{TL} \mathrm{da}^{-1}\right)$, sığır gübresi (2306.54 TL da $\left.{ }^{-1}\right)$ ve at gübresi + humik asit (2280.64 TL da $\mathrm{Tl}^{-1}$ ) uygulamaları izlemiş̧ir. Organik uygulamalar içerisinde en az net kâr1 (854.52 $\left.\mathrm{TL} \mathrm{da}^{-1}\right)$ denemenin tüm özelliklerinde en iyi performans gösteren deniz yosunu + sığır gübresi uygulamasında belirlenmiştir. Bunun nedeni bu uygulamanın toplam masrafi torf ve torf + humik asit dışında diğer organik gübrelerden daha yüksek çıkmasıdır. İkinci yı1 uygulamalar arasında en düşük üretim masrafi ise at gübresi (592.31 TL $\mathrm{da}^{-1}$ ) uygulamasında belirlenmiştir. 2011 yılında torf ve torf + humik asit dışındaki diğer organik gübre uygulamaların çoğu, geleneksel üretim sisteminden daha fazla kâr getirdiği görülmüştür. Denemenin ikinci yılında ilk yılda olduğu gibi ekonomik kârlılık sağlamayan uygulamalar, aynı zamanda en fazla üretim masrafina da sahip olan torf (-14994.74 TL $\left.\mathrm{da}^{-1}\right)$ ve torf + humik asit (-14413.84 $\left.\mathrm{TL} \mathrm{da}^{-1}\right)$ uygulamalarında alınmıştır. $\mathrm{Bu}$ uygulamalardan yüksek verim alınması ve satış fiyatının geleneksel sisteme göre yüksek olması üretim masraflarını karşılayamamış ve torf ile torf + humik asit uygulamalarından zarar edilmesine neden olmuştur.

Çalışmanın ikinci yılında, uygulamalar arasında brüt kârı, organik cin mısır yetiştiriciliği uygulamalarının çoğunda geleneksel cin mısır 
yetiştiriciliğinden (1741.88 TL da $\left.{ }^{-1}\right)$ daha yüksek bulunmuştur. Bunda organik ürünlerin $\mathrm{kg}$ satış fiyatının geleneksel sisteme nazaran daha yüksek olmasından kaynaklanmaktadır. Araştırma sonucunda, Diyarbakır koşullarında verim, kalite ve net kârlılık kriterleri göz önüne alınarak, organik cin mısır yetiştiriciliği için özellikle sığır gübresi, at gübresi, tavuk gübresi, kompost, koyun gübresi ile humik asit uygulamalarının tavsiye edilebilir ve ekonomik anlamda en uygun uygulamalar olduğu söylenebilir. Ancak torf uygulaması için ekonomik anlamda bir uygulama olduğu söylenemez. Bulgularımız ekolojik tahıl üretiminde net kâr düzeyinin geleneksel tarıma göre düşük olduğunu bildiren Dobbs et al (1988), Shafiq-ur-Rehman et al (2008), Acar et al (2009)'nn bulguları ile çelişirken, Cengiz et al (2010) ve Şahin et al (2010)'ın organik uygulamalardan alınan verimlerin ticari gübreden daha karlı olduğu belirten tespitleri ile uyum içerisindedir.

\section{Sonuç}

Bu çalışma ile Diyarbakır koşullarında organik cin mısırın yetiştirilebileceği belirlenmiştir. Araştırmada en yüksek tane verimi veren deniz yosunu + sığır gübresi ile güvercin gübre uygulamaları ekonomik bulunmamıştır. Ancak verim, kalite ve net kârlılık kriterleri göz önüne alındığında, organik cin mısır yetiştiriciliğinde at gübresi, tavuk gübresi, kompost, sığırgübresi, koyun gübresi ile humik asit kullanılabilir ve ekonomik anlamda en uygun uygulamalar olduğu söylenebilir. Ayrıca cin mısırında organik gübreler ile humik asidin birlikte uygulanmasının, organik gübrelerin tek olarak uygulanmasina nazaran daha iyi sonuç verdiği görülmüştür.

\section{Kaynaklar}

Acar M, Dok M \& Caner Y K (2009). Organik ve geleneksel tarım metodu ile üretilen nohut'un verim, maliyet ve kalite kriterleri bakımından karşılaştırılması. I. GAP Organik Tarım Kongresi, 1720 Kasım 2009, Şanlıurfa, s. 38-46

Açıkgöz N, İlker E \& GokcoL A (2004). Assessment of biological research on the computer. EU, TOTEM, No: 2, İzmir
Amanullah M M, Alagesan A, Vaiyapuri K, Pazhanivelan S \& Sathyamoorthi K (2006). Intercropping and organic manures on the growth and yield of cassava (Manihot esculenta Crantz.). Reseaerch Journal of Agriculture and Biological Sciences 2(5): 183-189

Amujoyegbe B J, Opabode J T \& Olayinka A (2007). Effect of organic and inorganic fertilizier on yield and chlorophyll content of maize (Zea mays L.) and Sorghum Bicolour (L.) Moenc. African Journal of Biotechnology 6(16): 1869-1873

Anaç D \& Okur B (1996). Toprak verimliliğinin doğal yollar ile artırılması. Ekolojik (Organik, Biyolojik) Tarım Organizasyon Derneği (ETO), İzmir, s. 37-73

Anonim (2011). Diyarbakır iline ait 2010, 2011 ve uzun yıllar iklim verileri. Diyarbakır Meteoroloji Bölge Müdürlüğü, Diyarbakır

Ashoka P, Anand S R, Mudalagiriyappa P \& Smitha R (2009). Effect of macro and micronutrients with organics on growth, quality, yield and economics of baby corn (Zea mays L.) in tungabhadra command area. Crop Research (Hisar) 37(1-3): 15-18

Bamire A S \& Amujoyegbe B J (2004). Economics of poultry manure utilization in land quality improvement among integrated poultry-maize holder farmers in Southwestern Nigeria. Journal of Sustainable Agriculture 23(3): 21-37

Beşirli G, Sönmez İ, Keçeci M \& Güçdemir İ H (2009). Organik domates yetiştiriciliğinde yeşil gübreleme ve bazı besin maddelerinin toprak yapısı üzerine etkisi. 1. GAP Organik Tarım Kongresi 17-20 Kasim 2009, Şanlıurfa, s. 583-591

Cengiz R, Yanıkoğlu S \& Sezer M C (2010). Sentetik ve organik gübrelerin misırda (Zea mays L.) verim ve kaliteye etkisi. (Ed: A A Vural), Organik Tarım Araştırma Sonuçları 2005-2010. T.C. Tarım ve Köyişleri Bakanlığı, Ankara, s. 213-220

Delate K \& Combardella C (2000). Comparison of organic and conventional crops at the nelly-kinyon long-term agroeciological research. 2000. Iova University. Armstrong Research an Demonstraion Farm Bulletin. 7: 208-210

Dobbs T L, Leddy M G \& Smolik J D (1988). Factor influencing the economic patential for alternative farming systems. Case Analyses in South Dakota. American Journal of Alternative Agriculture 3: 26-34

Dordas C A, Lithourgidis A S, Matsi T \& Barbayiannis N (2008). Application of liquid cattle manure and inorganic fertilizers affect dry matter, nitrogen 
accumulation, and partitioning in maize. Nutrient Cycling in Agroecosystems 80(3): 283-296

Efthimiadou A, Bilalis D, Karkanis A \& FroudWilliams B (2010). Combined organic/inorganic fertilization enhance soil quality and increased yield, photosynthesis and sustainability of sweet maize crop. Australian Journal of Crop Science 4(9): 722-729

Gao F, Cao L, Chen G \& Shi K (2003). Applied test and study on biological organic fertilizer in glutinous corn. Journal of Shanghai Jiaotong University-Agricultural Science 21(3): 237-241

Gerzabek M H \& Ulah S M (1988). Influence of fulvic and humic acids on the Zn uptake by corn (Zea mays L.) from nutrient solution. Mitteilungen der Deutschen Badenkundlichen Gesellschaft 56: 141-146

Gürses M A (2010). Misır (Zea mays indentata Sturt.) yetiştiriciliğinde değişik yeşil gübre ve çiftlik gübresi uygulamalarının verim ve verim unsurlarına etkisi. Yüksek lisans tezi, Çukurova Üniversitesi Fen Bilimleri Enstitüsü (Basılmamış), Adana

Kan A (2005). Sert misırda organik ve inorganik gübre dozlarının koçan püskülü verimi ve püsküldeki bitki besin elementi içerikleri üzerine etkileri. Türkiye VI. Tarla Bitkileri Kongresi, 5-9 Eylül 2005, Antalya (Araştırma Sunusu) Cilt I, s. 253-256

Khan H Z, Malik M A \& Saleem M F (2008). Effect of rate and source of organic material on the production potential of spring maize (Zea mays L.). Pakistan Journal of Agricultural Sciences 45(1): 40-43

Kün E (1997). Tahıllar II (Sicak iklim tahılları), Ankara Üniversitesi Ziraat Fakültesi Yayın No: 1452, Ders Kitabı No: 432, Ankara

Leaungvutivirog C, Sunantapongsuk V, Limtong P, Nakapraves P \& Piriyaprin S (2004). Effect of organic fertilizer on soil improvement in Mab Bon, Tha Yang, Satuk and Renu Series for Corn Cultivation in Thailand. Symposium, 14-21 August 2002, No: 57, Paper No: 1899

Lee Y S \& Bartlett R J (1976). Stimulation of plant growth by humic substances. Soil Science Society of American Journal 40: 876-879

Liu Y T (2003). A positioning study on applying organic fertilizer in maize field on dryland. Journal of Maize Sciences 11(2): 86-88

Mahesh L C, Kalyanamurthy K N, Ramesha Y M, Yogeeshappa H, Shivakumar K M \& Prakash H (2010). Effect of integrated nutrient management on growth and yield of maize (Zea mays L.). International Journal of Agricultural Sciences 6(1): 275-277

Manju B \& Mukerji K G (1994). Efficacy of root litter as a biofertilizer. Biology and Fertility of Soils 18(3): 228-230

Mitchell C C \& Tu S (2005). Long-term evaluation of pultry litter as a source of nitrogen for cotton and corn. Agronomy Journal 97: 399-407

Morris D R \& Lathwell D J (2004). Anaerobically digested dairy manure as fertilizer for maize in acid and alkaline soils. Communications in Soil Science and Plant Analysis 35(11-12): 1757-1771

Neill M \& Robinson K (2001). NMSU testing organic alternative to chemical fertilizers. New Mexica State University Research Bulletins 6: 2194-2195

Öktem A (1997). GAP bölgesinde mısır üretim olanakları. Harran Üniversitesi Ziraat Fakültesi Dergisi 1(2): 113-122

Prasanna K, Halepyati A S, Desai B K \& Pujari B T (2007). Effect of integrated nutrient management on the productivity and nutrient uptake by maize (Zea mays L.). Karnataka Journal of Agricultural Sciences 20(4): $833-834$

Resmi gazete (2010). Organik tarımın esasları ve uygulanmasına ilişkin yönetmelik. http://www. resmigazete.gov.tr/eskiler/2010/08/20100818-4.htm/ (Erişim tarihi: 18.08.2010)

Shafiq-ur-Rehman M A, Bukhsh A H A \& Ishaque M (2008). Comparative performance and profitability of two corn hybrids with organic and inorganic fertilizers. Pakistan Journal of Agricultural Sciences 45(3): 8-12

Sharif M, Ahmad M, Sarir M S \& Khattak R A (2004). Effect of organic and 1norganic fertilizers on the yield and yield components of maize. Pakistan Journal of Agriculture, Agricultural Engineering, Veterinary Sciences 20(1): 11-16

Şahin S, Atay S, Gökalp K, Çolak S, Demirtaş M N, Öztürk B, Yılmaz K U, Fidan Ş \& Çelik B (2011). Malatya yöresinde organik kayısı yetiştiriciliği. Organik Tarım Araştırma Sonuçları, T.C. Tarım ve Köyişleri Bakanlığı Tarımsal Araştırmalar Genel Müdürlüğü, Ankara, Türkiye, s. 51-56

Şeker C \& Ersoy İ (2005). Değişik organik gübreler ve leonarditin toprak özellikleri ve misır bitkisinin (Zea mays L.) gelişimi üzerine etkileri. Selçuk Üniversitesi Ziraat Fakültesi Dergisi 19(35): 46-50 
Thakur G D, Bavalgave V G, Waghmare M S, Kesare B J \& Khandekar B S (2009). Effect of fertilizer levels on growth and yield of sweet corn. International Journal of Agricultural Sciences 5(1): 100-102

Ülger A C (1998). Farklı azot dozu ve sira üzeri mesafelerinin patlak misirda (Zea mays everta Sturt.) tane verimi ve bazı tarımsal özelliklere etkisi. Çukurova Üniversitesi Ziraat Fakültesi Dergisi 13(1): 155-164

Vuruş H C, Çınar S \& Akdemir Ş (2000). Çukurova bölgesinde makarnalık buğdayın azotlu gübre kullanımının ekonomik analizi. Çukurova Üniversitesi Ziraat Fakültesi Dergisi 15(1): 85-90

Wang L H, Shi W D, Yang W Y \& Lİ C S (2003). Effect of different ratios of fertilizer application on yield and growth of hybrid maize seeds. Journal of Jilin Agricultural University 25(6): 643-648

Warman P R \& Munro-Warman T R (1993). Do seaweed extracts improve vegetable production? optimization of plant nutrition. Eighth international colloquium for the optimization of plant nutrition, 31 August-8 September 1992, Lisbon, Portugal. Dordrecht: Kluwer Academic Publishers, 1993, pp. 403-407

Yazıcı K \& Kaynak L (2001). Deniz yosunlarının organik tarımda kullanılma olanakları. Türkiye 2. Ekolojik Sempozyumu, 14-16 Kasim 2001, Antalya, s. 344-352

Yurtsever N (1984). Deneysel İstatistik Metotları. Toprak ve Gübre Araştırma Enstitüsü Genel Yayın No: 121, Ankara 